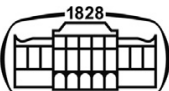

AKADÉMIAI KIADÓ

\title{
Herd immunization with childhood vaccination may provide protection against COVID-19
}

YONGQIANG YU ${ }^{1,2 *} \odot$

\section{Acta Microbiologica et Immunologica Hungarica}

67 (2020) 3, 198-200

D0l:

$10.1556 / 030.2020 .01207$

(c) 2020 Akadémiai Kiadó, Budapest

\section{LETTER TO THE EDITOR}

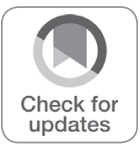

* Corresponding author.

E-mail: xiaolonger523@yahoo.ca

\section{AKJournals}

\section{ABSTRACT} future pandemics.

\section{KEYWORDS} intensive care unit $[6,7]$.
${ }^{1}$ Mindong Hospital, Fuan, Ningde, China

${ }^{2}$ The Affiliated Mindong Hospital of Fujian Medical University, Fuan, Ningde, China

Received: May 4, 2020 • Accepted: June 21, 2020

Published online: September 26, 2020

It may take time to obtain a vaccine for the current COVID-19, and the virus genome may keep an evolution and mutations, so a universal and effective vaccine for the coronavirus may not be possible. Epidemiological studies reveal the infection of SARS and COVID-19 in children is less frequent and less severe than in adults. Childhood vaccine-mediated cross cellular immunity and immunomodulation might provide protection against the infections of COVID-19. These data suggest that herd immunization with children vaccines in adults may improve the adult cross cellular immunity and immunomodulation and improve their clinical presentation and prognosis. This can be also useful to cope with

herd immunization, childhood vaccination, COVID-19

From Dec, 2019, an infection of a novel human coronavirus, named COVID-19 has been devastating the world [1-3]. Children are usually more susceptible to viral infection than adults do [4, 5], however, the incidence of COVID-19-infection and fatalities in children is very low. In the age group of 0-9 years old, the incidence of infections is between $0.5 \%$ and $0.9 \%$ with no fatalities; in the age group of $10-19$ years old, the infection rate is between $0.7 \%$ and $1.2 \%$ with the fatality rate of $0.2 \%$ or lower than $0.2 \%$. The infection symptoms in children are usually less severe than that in adults, children are rarely recovered in the

Coincidently, during the epidemic of severe acute respiratory syndrome (SARS) in 2003, people between 20 and 40 years old were the most susceptible to the infection of SARS [810], persons below the age of 20 were less susceptible, and the lowest incidence of morbidity and mortality were among the individuals between 0 and 9 years old [11-14]. In contrast to adult patients, the patients below 20 years of age usually experienced relatively mild symptoms and had a shorter duration of infection $[11,12,15,16]$.

Both children and adults were exposed to the same virulence of SARS/COVID-19, the specific immunological features of children might be the keystone to play a different interaction between the host immune system and SARS/COVID-19 resulting in different clinical outcomes between children and adults. The specific immunological features of children might be the vaccine-mediated trained immunity [17] and the immunomodulation which may benefit pediatric patients to mild their clinical presentation of SARS and COVID-19.

The innate immune cells (such as monocytes/macrophages) become memory cells after pathogen/vaccine exposure, the memory cells can produce either an enhanced or attenuated immune responses to the afterward exposure of the same or unrelated pathogens, which is defined as trained immunity and immunomodulation [18]. Attenuated immune responses is a kind of immunomodulation which can prevent the immune system from over-reacting against the invading pathogens, because an over-reacting immune response cannot make a distinction between self and non-self tissue leading to the unwanted damage to host tissues [19-22].

Vaccine-mediated enhanced trained-immunity is composed of the humoral (B-cells/ antibodies) and cellular immunity (T-cells). Natural killer (NK) cells can be from the B-cell 
and T-cell lineages, but NK cells are only involved in innate immune responses [23-25]. With the binding of the vaccineantigen to the B-cell receptor and secondary signaling from cytokines, the stimulated $\mathrm{B}$-cells begin to mature into a plasma cells and then produce of the particular antibody with the best corresponding fit to the vaccine-antigen [23, 24]. The particular antibody can provide protection against the specific reinfection of the vaccine-related pathogen. At the same time vaccine-mediated cellular-immunity (NK cells) and immunomodulation can confer non-specific cross protection to other invading pathogens [26-28].

For example, measles-vaccination cannot only reduce measles-associated fatality, but also very likely to decrease other infection-related mortality [29]. Influenza vaccine can confer the protection against flu, at the same time the vaccine is immune-modulator inducing NK cytotoxic response, one month after the vaccination of influenza the level of NK activity is still significantly higher than that before vaccination, in addition to provide immunity against flu infection, the elevated NK activity can prevent other viral infection [30].

In older children frequent vaccinations can stimulate the humoral immunity to generate antibodies providing effective protection to eliminate the reinfection of vaccine-related pathogens; and the vaccinations can activate the cellular immunity and modulate the immune system, protecting the host from other pathogen-associated infections, and preventing the over-reaction of immune system [29]. However in infants a state of partial immunization can induce a relatively immature trained immunity and low level of cross immunity, thus the clinical presentation of the infants infected with COVID-19 are more severe compared to that of the older children patients [31].

About $75-80 \%$ of the viral genome of the COVID-19 is identical to that of the SARS [32]. Genetic resemblance suggests that COVID-19 and SARS may share similar pathogenetic mechanisms $[33,34]$. It is a reasonable to speculate that the lower infectivity and fatality of SARS and COVID-19 in children is related to the cross-immunity elicited in children as a response to one or more of their childhood vaccines.

The effect of children vaccine-mediated humoral immunity on SARS had been investigated. The following vaccines had been tested, group A meningococcal polysaccharide, measles, rubella, Bacille Calmette-Guérin, mumps, diphtheria, pertussis, tetanus (DPT), Streptococcus pneumoniae, Japanese encephalitis, varicella, hepatitis B virus, oral poliovirus vaccine, and Haemophilus influenzae type b. Results showed these vaccines did not induce cross reactive antibodies against SARS [35]. However the authors did not investigate other possible cross-protective mechanisms: vaccine mediated cross protection of cellular immunity and immunomodulation.

Rotavirus vaccine was not tested in above study. The rotavirus vaccine helps protect people against diarrhea and vomiting caused by rotavirus, an interesting finding in the infection of COVID-19 is that, only $13 \%$ of pediatric patients of COVID-19 experience the symptoms of diarrhea, meanwhile $31 \%$ of adult patients of COVID-19 have the symptoms of diarrhea [36], in another report $48.5 \%$ of adult patients of COVID-19 have the symptoms of diarrhea [37]. The patients of COVID-19 with digestive symptoms, such as anorexia or loss of appetite, diarrhea, vomiting, and abdominal pain, have a worse clinical outcome and higher risk of mortality compared to those without digestive symptoms [37]. On the other hand, patients without digestive issues are more likely to be cured and discharged from the hospital [38]. The mild clinical presentations and the less frequent symptom of diarrhea in pediatric patients might be secondary to the cross cellular immunity and immunomodulation induced by children vaccination. In fact, it has been reported that vaccination can activate cellular immunity and immunomodulation [26-28].

It may take time to obtain a vaccine for the current COVID-19, and the virus genome may keep an evolution and mutations, so a universal and effective vaccine for the coronavirus may not be possible. My suggestion is herd immunization with children vaccines. We might try to vaccinate adults with children vaccines, we can assign the participants into various groups, such as the group of rotavirus vaccine, the group of measles vaccines, the group of flu vaccines, and the group of multiple vaccine combination, we can compare the effectiveness of different groups and optimize our vaccination design. The goal one is to increase cross cellular immunity, the goal two is to modulate adult immune system preventing it from over-reacting with COVID-19 infection. Vaccinating adults with children vaccine may not eradicate the infection of COVID-19 immediately, but the clinical presentation and patient prognosis might be improved, and the potential benefit far outweigh the risk.

Conflict of interest: We declare that there is no competing financial interest in relation to the work described. There is no conflict of interests at all.

\section{REFERENCES}

[1] www.who.int/dg/speeches/detail/who-director-general-s-openingremarks-at-the-media-briefing-on-covid-19-11-march-2020 WHO Director-General's opening remarks at the media briefing on COVID-19-11 March 2020.

[2] WHO www.who.int/docs/default-source/coronaviruse/situationreports/20200324-sitrep-64-covid-19.pdf?sfvrsn=703b2c40_2 Coronavirus disease 2019 (COVID-19) Situation Report - 64. Date last updated: March 24, 2020.

[3] Istituto Superiore di Sanità Sorveglianza Integrata COVID-19 in Italia www.epicentro.iss.it/coronavirus/bollettino/Infografica_24 marzo\%20ITA.pdf. Date last updated: March 24, 2020.

[4] Lee P, Hu YL, Chen PY, Huang YC, Hsueh PR. Are children less susceptible to COVID-19? J Microbiol Immunol Infec 2020: S1684-1182(20)30039-6.

[5] Monto AS, Ullman BM. Acute respiratory illness in an American community. The Tecumseh Study. JAMA 1974; 227: 164-9. https://doi.org/10.1001/jama.1974.03230150016004 [PubMed: 4357298]. 
[6] Novel Coronavirus Pneumonia Emergency Response Epidemiology Team [The epidemiological characteristics of an outbreak of 2019 novel coronavirus diseases (COVID-19) in China]. Zhonghua Liu Xing Bing Xue Za Zhi 2020; 41: 145.

[7] Istituto Superiore di Sanità www.epicentro.iss.it/coronavirus/ bollettino/Bollettino-sorveglianza-integrata-COVID-19_23-marzo \%202020.pdf Epidemia COVID-19 Aggiornamento Nazionale. Date last updated March 23, 2020.

[8] You Z, Xin S. Clinical analysis of severe acute respiratory syndrome. Med J Chin PLA 2003; 28: 1126.

[9] Li Z, Shen K, Wei X. Clinical analysis of pediatric SARS case in Beijing. Chin J Pediatr 2003; 41: 574.

[10] Li A, Chan C, Chan D. Long-term sequelace of SARS in Children. Paediatr Respir. Rev 2004; 5: 296-9.

[11] Bitnun A, Allen U, Heurter H, King SM, Opavsky MA, Ford-Jones EL, et al.. Children hospitalized with severe acute respiratory syndrome-related illness in Toronto. Pediatrics 2003; 112: 261.

[12] Wallace S. Studies indicate disease was mild in children: SARS baffles researchers. AAP News 2003; 23: 145.

[13] Leung C-W, Kwan Y-W, Ko P-W, Chiu SS, Loung P-Y, Fong N-C, et al. Severe acute respiratory syndrome among children. Pediatrics 2004; 113: 535.

[14] Van Bever H, Hia C, Chye Q. Childhood SARS in Singapore. Arch Dis Child 2003; 88: 742.

[15] Liu L, Zheng H, Lu H. Clinical presentation and outcomes of the severe acute respiratory syndrome in children. Pediatr Emerg Med 2003; 10: 188.

[16] Liu JH, Ma SX, Ouyang XL, Wang HB, Yu Y, Li XJ, et al. Determination and comparison of anti-SARS antibody in children and adults, Zhongguo Shi Yan Xue Ye Xue Za Zhi 2004; 12(2): 217-9.

[17] Cristiani L, Mancino E, Matera L, Nenna R, Pierangeli A, Scagnolari $\mathrm{C}$, et al. Will children reveal their secret? The coronavirus dilemma. J Expl Haematol 2004; 12: 217.

[18] Cao Q, Chen Y-C. SARS-CoV-2 infection in children: Transmission dynamics and clinical characteristics. J Formos Med Assoc 2020; 119: 670-3.

[19] Long GH, Chan BHK, Allen JE, Read AF, Graham AL. Experimental manipulation of immune-mediated disease and its fitness costs for rodent malaria parasites. BMC Evol Biol 2008; 8: 128.

[20] Sorci G, Faivre B. Inflammation and oxidative stress in vertebrate host-parasite systems. Phil Trans R Soc B 2009; 364: 71-83.

[21] Chaplin DD. Overview of the immune response. J Allergy Clin Immunol 2010 Feb; 125(2 Suppl. 2): S3-23.

[22] Sorci G, Cornet S, Faivre B. Immune evasion, immunopathology and the regulation of the immune system. Pathogens 2013 Mar; 2(1): 71-91.

[23] Goldsby RA, Kindt TJ, Osborne BA, Kuby J. New York: Freeman; 2003 [Google Scholar].

[24] The merck manuals online medical library; 2008. Components of the Immune System. [Last cited on 2009 Nov 26]. Available from: http://www.merck.com/mmpe/sec13/ch163/ch163b.html.
[25] Angela SC. Fundamentals of vaccine immunology. J Glob Infect Dis 2011 Jan-Mar; 3(1): 73-8.

[26] Desselberger U, Huppertz HI. Immune responses to rotavirus infection and vaccination and associated correlates of protection. J Infect Dis 2011 Jan 15; 203(2): 188-95.

[27] Kaufhold RM, Field JA, Caulfield MJ, Wang S, Joseph H, Wooters MA, et al. Memory T-cell response to rotavirus detected with a gamma interferon enzyme-linked immunospot assay. J Virol 2005; 79(9): 5684-94.

[28] Sestak, K, McNeal, MM, Choi A, Cole MJ, Ramesh G, Alvarez X, et al. Defining T-cell-mediated immune responses in rotavirusinfected juvenile rhesus macaques. J Virol 2004; 78(19): 10258-64.

[29] Christine SB, Mihai GN. A small jab - a big effect: nonspecific immunomodulation by vaccines. Trends Immunol 2013; 34: 431-9. https://doi.org/10.1016/j.it.2013.04.004 [PubMed: 23680130] [CrossRef: 10.1016/j.it.2013.04.004].

[30] Myśliwska J, Trzonkowski P, Szmit E, Brydak LB, Machała M, Myśliwski A. Immunomodulating effect of influenza vaccination in the elderly differing in health status. Exp Gerontol 2004; 39: $1447-58$.

[31] Dong Y, Mo X, Hu Y, Qi X, Jiang F, Jiang Z. Epidemiological characteristics of 2143 pediatric patients with 2019 coronavirus disease in China. Pediatrics 2020: e20200702. [PubMed: 32179660].

[32] Zhou P, Yang XL, Wang XG, Hu B, Zhang L, Zhang W, et al. A pneumonia outbreak associated with a new coronavirus of probable bat origin, Nature 2020; 579: 270-3.

[33] Prompetchara E, Ketloy C, Palaga T. Immune responses in COVID-19 and potential vaccines: Lessons learned from SARS and MERS epidemic. Asian Pac J Allergy Immunol 2020; 38: 1-9. https://doi.org/10.12932/AP-200220-0772 [PubMed: 32105090] [CrossRef: 10.12932/AP-200220-0772].

[34] Newton AH, Cardani A, Braciale TJ. The host immune response in respiratory virus infection: balancing virus clearance and immunopathology. Semin Immunopathol 2016; 38: 471-82.

[35] Yu, Y, Jin HJ, Chen Z, Nenna R, Pierangeli A, Scagnolari C, et al. Children's vaccines do not induce cross reactivity against SARSCoV. J Clin Pathol 2007 Feb; 60(2): 208-11.

[36] CDC COVID-19 Response Team, US Department of Health and Human Services/Centers for Disease Control and Prevention. Morbidity and Mortality Weekly Report: Coronavirus Disease 2019 in Children - United States, February 12-April 2, 2020. April 10, 2020/Vol. 69/No. 14.

[37] Groth L. Is diarrhea a symptom of Covid-19? | Health.com https:// www.health.com/condition/infectious-diseases/coronavirus/isdiarrhea-a-symptom-of-covid-19 1/3. 4/10/2020.

[38] Pan L, Mu M, Yang P, Sun Y, Wang R, Yan J, et al. Clinical characteristics of COVID-19 patients with digestive symptoms in Hubei, China: a descriptive, cross-sectional, multicenter study, Am J Gastroenterol 2020 Mar 26; 115(5): 766-73. 